University of Nebraska - Lincoln

DigitalCommons@University of Nebraska - Lincoln

$11-15-1991$

\title{
Sputtering pressure effect on microstructure of surface and interface, and on coercivity of Co/Pt multilayers
}

\author{
Ping $\mathrm{He}$ \\ University of Nebraska - Lincoln \\ William A. McGahan \\ University of Nebraska - Lincoln \\ S. Nafis \\ University of Nebraska - Lincoln \\ John A. Woollam \\ University of Nebraska-Lincoln, jwoollam1@unl.edu \\ Z.S. Shan \\ University of Nebraska - Lincoln \\ See next page for additional authors
}

Follow this and additional works at: https://digitalcommons.unl.edu/physicsliou

Part of the Physics Commons

He, Ping; McGahan, William A.; Nafis, S.; Woollam, John A.; Shan, Z.S.; Liou, Sy_Hwang; Sequeda, F.; McDaniel, T.; and Do, H., "Sputtering pressure effect on microstructure of surface and interface, and on coercivity of Co/Pt multilayers" (1991). Si-Hwang Liou Publications. 47.

https://digitalcommons.unl.edu/physicsliou/47

This Article is brought to you for free and open access by the Research Papers in Physics and Astronomy at DigitalCommons@University of Nebraska - Lincoln. It has been accepted for inclusion in Si-Hwang Liou Publications by an authorized administrator of DigitalCommons@University of Nebraska - Lincoln. 


\section{Authors}

Ping He, William A. McGahan, S. Nafis, John A. Woollam, Z.S. Shan, Sy_Hwang Liou, F. Sequeda, T. McDaniel, and H. Do 


\title{
Sputtering pressure effect on microstructure of surface and interface, and on coercivity of Co/Pt multilayers
}

\author{
Ping He, William A. McGahan, S. Nafis, John A. Woollam, Z. S. Shan, and S. H. Liou \\ Center For Microelectronic and Optical Materials Research, and Departments of Physics and Electrical \\ Engineering, University of Nebraska, Lincoln, Nebraska 68588-0511
}

F. Sequeda, T. McDaniel, and H. Do

IBM Storage Systems Products Division, San Jose, California 95193

\begin{abstract}
Thin $\mathrm{Co} / \mathrm{Pt}$ multilayers were prepared on $\mathrm{Si}$ and glass substrates by sputtering with $\mathrm{Ar}$ pressures ranging from 2.5 to 15 mTorr. The bilayer structure of the samples was $\operatorname{Co}(3 \AA) /$ $\operatorname{Pt}(15 \AA) \times 17$, and all samples had the easy axis of magnetization perpendicular to the sample surface as determined with a SQUID magnetometer. All samples retained the layered structure, as revealed by low-angle $\mathrm{x}$-ray diffraction. In addition, diffraction peaks due to the formation of Co-Pt compounds (presumably at the interfaces between $\mathrm{Co}$ and $\mathrm{Pt}$ ) were identified. The coercivity of samples changed from about 400 Oe for films deposited at low Ar sputtering pressure (2.5 mTorr) to as high as 2300 Oe for films deposited at high $\mathrm{Ar}$ pressure ( $15 \mathrm{mTorr}$ ). Ellipsometry and atomic force microscopy were used to study surface roughness and microstructure of samples prepared at different sputtering pressures.
\end{abstract}

\section{INTRODUCTION}

$\mathrm{Co} / \mathrm{Pt}$ multilayer (ML) films made by different techniques, such as molecular beam epitaxy, electron-beam evaporation, and sputtering, have been intensively studied in the past few years because of their important potential application as optical data storage media. ${ }^{1-4}$ It is well known that the magneto-optical, and magnetic properties (such as Kerr effect and coercivity) of $\mathrm{Co} / \mathrm{Pt}$ ML films depend strongly on the deposition method. ${ }^{4,5}$ Experiments have shown that electron-beam evaporated $\mathrm{Co} / \mathrm{Pt} \mathrm{ML}$ films have higher coercivity than sputtered $\mathrm{Co} / \mathrm{Pt} \mathrm{ML}$ films. However, the Kerr rotation of evaporated Co/Pt ML films is smaller than that of sputtered films. Also, $\mathrm{Co} / \mathrm{Pt}$ ML films deposited using different sputtering gases, including $\mathrm{Ar}, \mathrm{Xe}$, and $\mathrm{Kr}$, were studied, and a systematic change of coercivity on sputtering gas species was found. ${ }^{5}$ But origins of the change of the coercivity in these films remained unclear because no differences in microstructure such as grain size were found in the films.

It was also unclear whether the crystalline alloy $\mathrm{Co}_{x} \mathrm{Pt}_{1-x}$ forms or not at interfaces between the $\mathrm{Co}$ and $\mathrm{Pt}$ layers, or if compounds form. Due to the fact that Co and $\mathrm{Pt}$ are miscible over the complete composition range ${ }^{6}$ and that sputter deposition does not result in atomically sharp interfaces, it is likely that the crystalline alloys $\mathrm{Co}_{x} \mathrm{Pt}_{1-x}$ form at interfaces between $\mathrm{Co}$ and $\mathrm{Pt}$. Compound formation was indicated in our previous work, ${ }^{4}$ as well as by others. ${ }^{7}$ However, there is still some controversy concerning this formation. A major purpose of the paper is to present clear evidence in favor of compound formation.

\section{EXPERIMENTS}

$\mathrm{Co} / \mathrm{Pt} \mathrm{ML}$ films were sputter deposited on $\mathrm{Si}$ wafers, as well as on glass at different $\mathrm{Ar}$ gas pressures, at room temperature. The nominal structure of the samples is $\mathrm{Co}(3$ $\AA) / \operatorname{Pt}(15 \AA) \times 17$ with a $300-\AA \mathrm{Pt}$ underlayer, as listed in
Table I. Both low, and high-angle $\mathrm{x}$-ray diffraction spectra were taken to verify the layered structure and to investigate the interface crystallinity with a Rigaku $x$-ray diffractometer, using $\mathrm{Cu} K_{\alpha}$ radiation $(\lambda=1.542 \AA)$. Magnetooptical polar Kerr rotation $\theta_{k}$ and coercivity $H_{\mathrm{cl}}$ were measured on a magneto-optical polar Kerr effect spectrometer described elsewhere. ${ }^{9}$ The coercivity $H_{c \perp}$ of the samples was determined from Kerr rotation hysteresis loops measured at a wavelength of $5000 \AA$, with applied magnetic fields over the range from 0 to $\pm 8 \mathrm{kG}$ magnetic, fields oriented perpendicular to the sample surface. The microscopic surface roughness of the samples was examined by ellipsometry and by atomic force microscopy (AFM). The experimental results for films deposited on glass substrates are almost identical to the results from films on $\mathrm{Si}$ wafers. The results shown in the next section are from films on $\mathrm{Si}$ wafers except for the x-ray diffractograms which are of films on glass, since then there is no peak showing up from the substrate.

\section{RESULTS AND DISCUSSION}

A typical low angle $x$-ray diffractogram from sample 1 deposited in Ar gas of 2.5 mTorr in Fig. 1 demonstrates the integrity and periodicity of the layered structure of samples. The two diffractograms (a) and (b) in Fig. 2 are from samples 2(5.0 mTorr) and 3(8.5 mTorr), respectively. The peaks around $2 \theta \cong 40^{\circ}$ in the $x$-ray diffractograms reveal that the films were at least partially crystalline, and the $\mathbf{P t}$ and $\mathrm{CoPt}_{3+\delta}$ ( $\delta$ is a small number) phases are identified as shown in Figs. 2(a) and 2(b). The diffractograms of samples $1(2.5 \mathrm{mTorr})$ and $2(5.0 \mathrm{mTorr})$ are similar, as are the diffractograms of samples 3 ( $8.5 \mathrm{mTorr}$ ) and $4(15.0 \mathrm{mTorr})$. Other parameters associated with these samples can be found in Table $I$.

The peak at $2 \theta \cong 40^{\circ}$ in Fig. 2(a) is mainly due to the (111) planes of Pt layers and the Pt underlayer, which are parallel to the film surface. The second-order Pt(111) peak 
TABLE I. Sample structures and other parameters.

\begin{tabular}{|c|c|c|c|c|}
\hline Sample No. & 1 & 2 & 3 & 4 \\
\hline $\mathrm{Co} / \mathrm{Pt}$ & \multicolumn{4}{|c|}{$3 \AA \AA \mathrm{Co} / 15 \AA \mathrm{Pt}$ for all samples } \\
\hline No. of bilayers & \multicolumn{4}{|c|}{17 bilayers on $300 \AA$ Pt buffer for all samples } \\
\hline$\lambda_{L}(\AA)$ & 17.8 & 20.3 & 20.7 & 17.7 \\
\hline Substrate & \multicolumn{4}{|c|}{ Si wafer } \\
\hline $\operatorname{Ar} P_{s}\left(\times 10^{-3}\right.$ Torr $)$ & 2.5 & 5.0 & 8.5 & 15 \\
\hline$H_{c 1}(\mathrm{Oe})$ & 416 & 833 & 1875 & 2291 \\
\hline
\end{tabular}

Note: $\operatorname{Ar} P_{S}=\operatorname{Ar}$ sputtering pressure: $H_{c l}=$ coercivity. $\lambda_{L}=$ bilayer thickness.

labeled $\mathrm{Pt}(222)$ is also visible at about $2 \theta \cong 86.4^{\circ}$ as shown in Fig. 2(a). The existence of the satellite peak ${ }^{9}$ at about $2 \theta=35.5^{\circ}$ shows that the film possesses superlattice structure character. From the difference of angular positions of the satellite peak and of the main peak labeled $\mathrm{Pt}(111)$ at about $40^{\circ}$, the bilayer thickness in the multilayers can be calculated.

When the sputtering pressure is increased, the peak at $2 \theta \cong 40^{\circ}$ splits into the two peaks shown in Fig. 2(b), which have been identified as being from $\mathrm{Pt}(111)$ and $\mathrm{CoPt}_{3+\delta}(111)$, respectively. From the angular position of the satellite peak at $2 \theta=36.1^{\circ}$ and bilayer thickness of the film, one can estimate that the position of the main superlattice peak should be at about $2 \theta=40.5^{\circ}$, which is the position of the $\mathrm{CoPt}_{3}+\delta(111)$ peak. Therefore, the crystalline structure in the layered region has changed. It is rather difficult to positively determine the phase structure in nanostructured multilayers. We address this question by looking for higher-order $\mathrm{x}$-ray diffraction peaks.

It is clear that there exist two weak peaks at $2 \theta=85.7^{\circ}$ and $87.4^{\circ}$ as shown in Fig. 2(b): These two peaks have been identified as the second-order peaks of $\mathrm{Pt}(111)$ and $\mathrm{CoPt}_{3+\delta}(111)$ labeled $\mathrm{Pt}(222)$ and $\mathrm{CoPt}_{3+\delta}(222)$, respectively. The existence of the second-order peak at $2 \theta$ $=87.4^{\circ}$ is strong evidence that there exists anot her crystalline structure with a $d$ spacing of $2.22 \AA$ which happens to be the $d$ spacing of $\mathrm{CoPt}_{3}(111)$ planes.

The detailed mechanism of how the $\mathrm{CoPt}_{3+\delta}$ compound forms is not clear. One explanation comes from examining the chemical interactions between $\mathrm{Co}$ and $\mathrm{Pt}$.

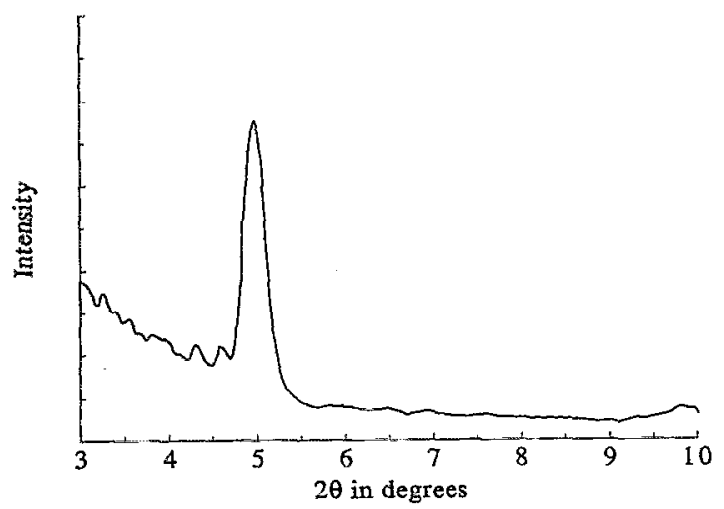

FIG. 1. Low-angle $x$-ray diffractogram of sample 1 . The peak indicates the bilayer thickness $17.8 \AA$.

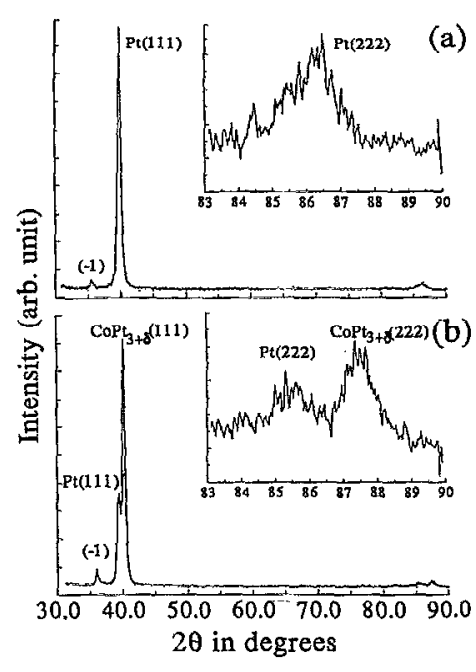

FIG. 2. High-angle $x$-ray diffractograms of samples $2(a)$ and 3(b).

According to the Miedema model, ${ }^{10}$ the heat of mixing for $\mathrm{Co}$ and $\mathrm{Pt}$ is negative $(-11 \mathrm{~kJ} / \mathrm{g}$ at. for $\mathrm{CoPt})$. This thermodynamic condition may result in sufficient kinetic mobility for $\mathrm{Co}$ and $\mathrm{Pt}$ atoms. In studies of sputter deposited $\mathrm{Ti} / \mathrm{Ni}^{11}$ and $\mathrm{Ni} / \mathrm{Zr}^{12}$ multilayers, it was found that the stability against interdiffusion was higher in films deposited at low deposition pressure. Also, from our previous study ${ }^{4}$ of evaporated and sputtered Co/Pt ML films, there is another peak corresponding to a $d$ spacing of $1.915 \AA$. This peak was present in diffractograms of three of our samples. The peak was identified as being from $\mathrm{CoPt}_{3}(200)$.

Figure 3 shows the systematic changes of coercivity $H_{c L}$ and Kerr rotation $\theta_{k}$ of the films with different sputtering gas pressures. A high coercivity $(1800 \mathrm{Oe})$ is obtained when the sputtering gas pressure is more than 8 mTorr (in the case of samples 3 and 4). All samples show $100 \%$ remanence in the perpendicular direction. The Kerr rotation decreases with increasing Ar pressure, as shown in Fig. 3. The decrease in Ker rotation may be related to the interfacial structure in $\mathrm{Co} / \mathrm{Pt} \mathrm{ML}$ films. But this point has not been fully studied.

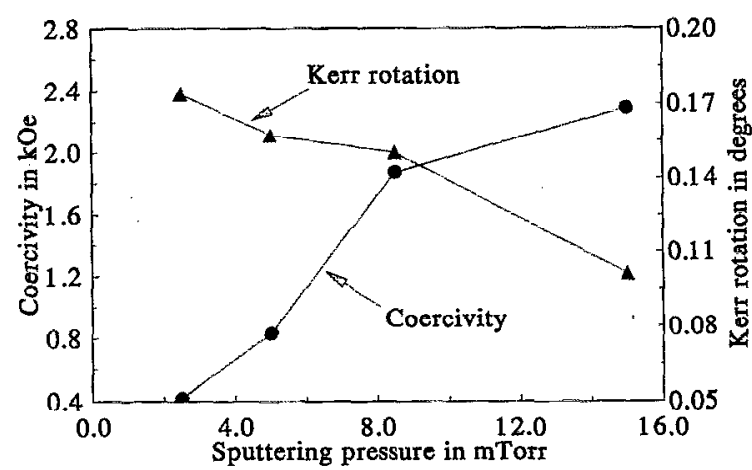

FIG. 3. Coercivity $H_{c \perp}$ and Kerr rotation $\theta_{k}$ of samples $1,2,3$, and 4 . $H_{c 1}$ in kOe and $\theta_{k}$ in degrees were determined from Kerr rotation loops measured at $\lambda=5000 \AA$ in magnetic field 0 to $\pm 8 \mathrm{kG}$. 


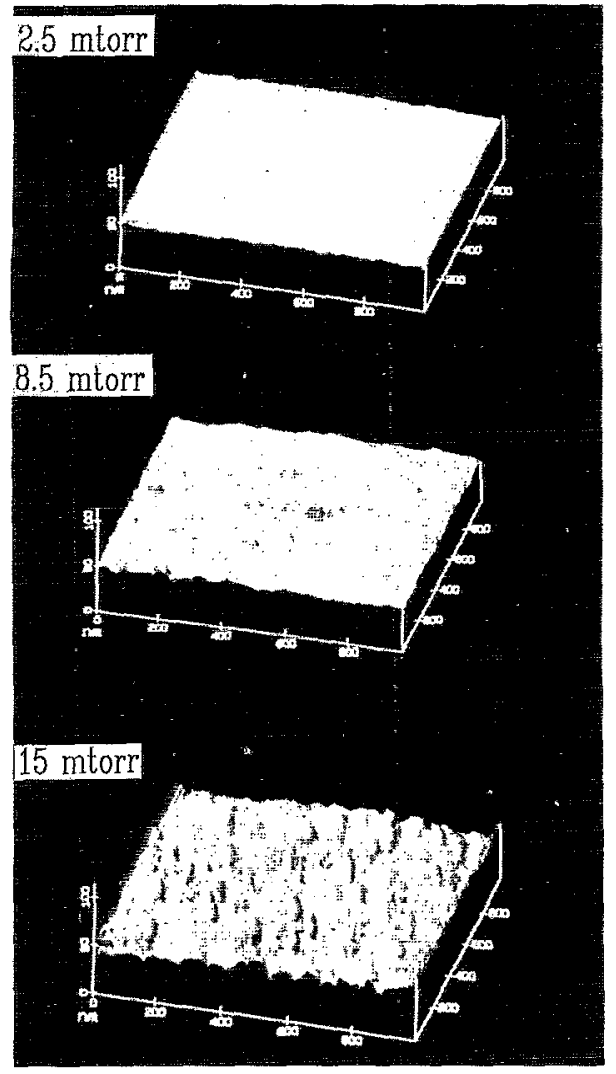

FIG. 4. Surface-views of AFM images of samples 1, 3, and 4. Units are nanometers.

The AFM images in Fig. 4 show the surface microstructures of samples 1(a), 3(b), and 4(c). Figure 4 reveals that at low sputtering pressures [e.g., $2.5 \mathrm{mTorr}$, Fig. 4(a)], the surface is very smooth and the grain size is very small. The average grain size for the low sputtering pressure is about $200 \AA$. When the sputtering pressure is increased, the films are not as dense, and the average grain size is considerably increased (to more than $1000 \AA$ ), as shown in Fig. 4(c). The surface roughness of the samples determined ellipsometrically is shown in Fig 5. The ellipsometrically determined roughness layer thickness on the surface is consistent with AFM images. The surface roughness of thin films (a few hundred Angstroms thick) is qualitatively related to the grain size. The smoother the surface, the smaller the grain size.

All the experimental results shown above suggest that the sputtering pressure or the bombardment of energetic ions reflected from target while sputtering change the microstructure of films. Sufficient ion bombardment of the films will smooth the surfaces, reduce the size of grains, and make the films dense, as indicated by Hashimoto et $a l .{ }^{13}$ While in the absence of ion bombardment, grains in the films will be large and surfaces rough. Since, in general, the coercivity, strongly depends upon the shape and size of grains in the materials, the increase in coercivity of the samples with increase in sputtering gas pressure can be at least partially attributed to the change in film microstruc-

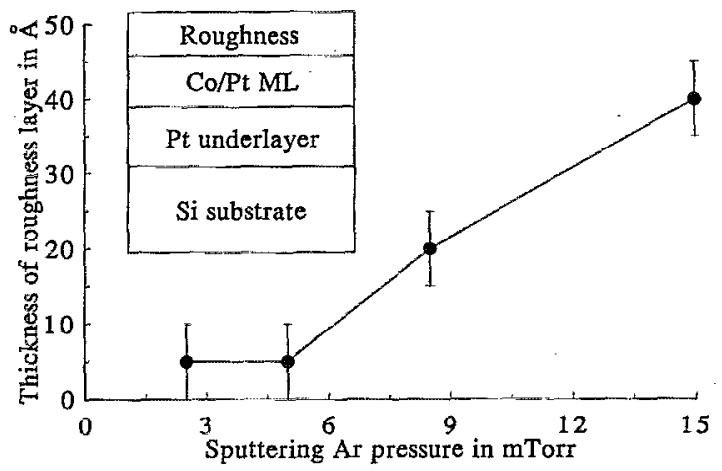

FIG. 5. Ellipsometrically analyzed thickness of surface roughness layer of samples 1, 2, 3, and 4, and the model on which the analysis was based.

ture. It should be pointed out that Co/Pt ML films are highly optically absorptive, and coercivity measurements using the Kerr rotation spectrometer are sensitive only to the first few hundred Angstroms of film. In other cases where films are very thick and the microstructure on the film surfaces are different from the interior of films, the coercivity as determined by the optical method may be different from that determined by the magnetic method which takes an average over the whole film. The coercivities determined by SQUID and by Kerr rotation loops of the samples in this study are about the same, since the film thickness of all the samples is only $300 \AA$.

\section{ACKNOWLEDGMENTS}

The authors acknowledge the assistance of $\mathrm{R}$. D. Kubik and R. Synowicki for surface roughness studies by atomic force microscopy, and helpful conversation with Ping Huang. The research at the University of Nebraska was supported by NSF grant DMR 8918889 .

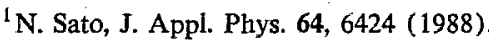

${ }^{2}$ W. B. Zeper, F. J. A. M. Greidanus, P. F. Carica, and C. R. Fincher, J. Appl. Phys. 65, 4917 (1989).

${ }^{3}$ Y. Ochiai, S. Hashimoto, and K. Aso, IEEE Trans. Mag. 25, 3755 (1989).

${ }^{4}$ P. He, W. A. McGahan, J. A. Woollan, F. Sequeda, T. McDaniel, and H. Do, J. Appl. Phys. 69, 4021 (1991).

${ }^{5}$ P. F. Carcia, S. I. Shah, and W. B. Zeper, Appl. Phys. Lett. 56, 2345 (1990).

${ }^{6}$ A. S. Darling, Platinum Metals Rev, 10, 14 (1966).

${ }^{7}$ R. F. C. Farrow, C. H. Lee, C. J. Lin, E. E. Marinero, and C. J. Chien, The Proceedings of The 35th Annual Conference on Magnetism and Magnetic Materials, San Diego, CA, Oct. 28-Nov. 1, 1990.

${ }^{8}$ L. Y. Chen and J. A. Woollam, SPIE 1166, 267 (1989).

${ }^{9}$ D. B. McWhan, "Structure of Chemically Modulated Films" in Synthetic Modulated Structures, edited by L. L. Chang and B. C. Giessen (Academic, Orlando, FL, 1985).

${ }^{10}$ A. R. Miedema, Philips Tech. Rev. 36, 217 (1976).

${ }^{11}$ B. M. Clemens, J. Appl. Phys. 61, 4525 (1987).

${ }^{12}$ R. J. Highmore, R. E. Somekh, J. E. Evetts, and A. L. Greer, J. Less Common Met. 140, 353 (1988).

${ }^{13}$ S. Hashimoto, Y. Ochiai, and K. Aso, J. Appl. Phys. 66, 4909 (1989). 